\title{
Structure et fonctionnement du réseau hanbalite bagdadien dans les premiers temps de la domination seldjoukide (milieu du $\mathrm{v}^{\mathrm{e}} / \mathrm{xl}^{\mathrm{e}}$ siècle)
}

\author{
Vanessa Van Renterghem \\ Institut national des langues et civilisations orientales, Paris
}

Dans une enquête d'histoire sociale, l'étude des réseaux sociaux, compris comme des ensembles de personnes entretenant des relations directes avec, sinon tous les autres membres, du moins un bon nombre d'entre eux, sans nécessiter pour autant la présence simultanée de tous les membres, permet une approche pragmatique, fondée sur l'observation des pratiques. Encore faut-il disposer de sources permettant d'observer de telles relations ; or, pour les sociétés du dār al-islām médiéval, la majeure partie des sources historiographiques disponibles (les dictionnaires biographiques au premier titre) regroupent les personnalités éminentes d'une ville ou d'une époque donnée en fonction d'une communauté d'activité (transmission du savoir traditionnel, exercice de fonctions judiciaires ou politico-administratives, production littéraire, etc.), limitant l'observation des réseaux aux liens établis entre des personnages ayant exercé ces activités et laissant dans l'ombre les éventuels acteurs appartenant à d'autres sphères (commerçants, militaires, personnes n'appartenant ni aux milieux lettrés, ni à ceux du pouvoir).

En conséquence, les seuls réseaux qu'il est possible de reconstituer à partir de ces sources sont internes aux sphères décrites: réseaux de transmission du savoir, étudiés à travers les relations maîtres-disciples ; réseaux mystiques à partir des ouvrages consacrés aux soufis ; réseaux de clientèle établis entre milieux du pouvoir et milieux lettrés... Mais faute de source qui s'y prête, il est plus difficile d'appréhender les réseaux transcendant les limites de ces groupes d'activité.

\section{Une source originale : le « Journal » d'Abū 'Alī ibn al-Bannā'}

La société bagdadienne du début de la période seldjoukide (premières décennies de la seconde moitié $d u v^{e} / x^{e}$ siècle) représente un terrain intéressant pour observer de façon privilégiée certains réseaux sociaux, en raison de l'existence d'une source originale produite par l'un des acteurs de l'époque : le « Journal » d'Abū 'Alīi ibn al-Bannā'. Il s'agit d'un ensemble de notes prises, au jour le jour, par un lettré hanbalite résidant dans le quartier 
de Bāb al-marātib, sur la rive orientale de Bagdad, au sud des quartiers califaux. Ces notes représentaient une sorte d'aide-mémoire pour leur auteur, en vue de la composition d'ouvrages postérieurs, et n'étaient sans doute pas destinées à être diffusées telles quelles ; certaines d'entre elles sont cependant parvenues par la suite entre les mains d'historiens arabes, qui les citent dans leurs ouvrages en accordant à l'ensemble le titre de Ta'rih (« histoire, chronique ») $)^{1}$. Une partie fragmentaire de ces notes, sous la forme d'un unicum autographe conservé à Damas, a été éditée et traduite en anglais par George Makdisi dans les années 1950 sous le titre de « Journal » (diary)² ; nous conservons ici cette dénomination qui met bien en valeur l'originalité de la source, fondée sur son caractère à la fois subjectif et quotidien.

Les fragments conservés du « Journal » (185 paragraphes de longueur variable) consignent les activités quotidiennes d'Ibn al-Bannā', lettré né à la fin $\mathrm{du} \mathrm{IV}^{\mathrm{e}} / \mathrm{x}^{\mathrm{e}}$ siècle, versé en transmission du hadīt et en droit musulman (figh), fervent adepte du madhab hanbalite et personnalité incontournable de son quartier, entre les mois de šawwāl 460/août 1068 et dū l-qa'da $461 /$ septembre 1069. Les événements, tous inscrits dans un cadre local, sont consignés par ordre chronologique et concernent tous les aspects de la vie quotidienne de l'auteur: ses activités dans le domaine de la transmission du savoir traditionnel (Ibn al-Bannā' enseignait le figh et le coran dans divers endroits de Bagdad), des pratiques religieuses communautaires (direction de la prière du vendredi ou des prières funéraires collectives) ou individuelles (prières, visites aux morts, lecture du coran) et de la sociabilité de quartier (visites de voisinage, assistance aux événements sociaux : mariages et autres cérémonies). Le « Journal » recense aussi les principales nouvelles apprises par l'auteur, par le truchement de sources d'informations variées allant des lettres de commerçants à la rumeur publique ; il rapporte ainsi les principaux événements de la vie politique bagdadienne (le limogeage du vizir du calife et la nomination d'un nouveau vizir par exemple) également recensés par les grandes chroniques s'intéressant à l'histoire de Bagdad, tout en offrant une multitude de détails et d'anecdotes absents des autres ouvrages historiographiques.

1. Par exemple Ibn al-Ğawzī (m. 597/1201) dans sa Chronique bien ordonnée (Kitāb al-Muntazam fïl-ta'rīh), au mois de ğumādā 1 460/mars 1068 (éd. critique par Muhammad et Mușțafā 'Abd al-Qādir 'Ațā, Beyrouth, 1992, vol. 16, p. 105).

2. Ibn al-Bannā' (m. 471/1079), «Journal », éd. du texte arabe et trad. angl. par G. Makdisi, " Autograph Diary of an Eleventh-Century Historian of Baghdād », Bulletin of the School of Oriental and African Studies 18, 1956, p. 9-31 et 239-260 ; 19, 1957, p. 13-48, 281-303, 426-443 (= History and Politics in Eleventh-Century Baghdad, Londres, 1990). Dans la suite de l'article, les références au texte d'Ibn al-Bannā' (désormais : " Journal ») seront données à partir de la numérotation par paragraphes établie par Makdisi. 


\section{Le contexte : Bagdad sous la domination seldjoukide}

Cette source apporte ainsi un éclairage original sur la vie quotidienne dans la capitale abbasside dans les premières années de la domination des Turcs seldjoukides, et sur les manifestations concrètes de cette domination. En 460-61/1068-69, l'autorité seldjoukide sur Bagdad et sur le califat abbasside était établie depuis une bonne dizaine d'années ${ }^{3}$, mais les sultans étaient rarement présents physiquement dans la ville ${ }^{4}$, où ils étaient représentés par un fonctionnaire portant le titre de šihna et par un certain nombre de dignitaires politiques et militaires. Le " Journal » d'Ibn al-Bannā' se fait l'écho du caractère quelque peu lointain et abstrait de la domination seldjoukide sur Bagdad, mais aussi de l'atmosphère très tendue régnant dans les milieux traditionalistes, dans un contexte de rétablissement d'un sunnisme d'État mais aussi et surtout de favoritisme envers deux écoles de droit sunnites qui n'étaient pas les plus fortement représentées à l'échelle locale : les madhab-s hanafite et šāfi ite, jouissant de l'appui des milieux seldjoukides ${ }^{5}$. Dans cette configuration, le madhab hanbalite, auquel appartenaient Ibn al-Bannā' et la plupart des personnes avec qui il entrait en interaction sociale, se trouvait dans une position politiquement marginale bien qu'il fût solidement implanté à Bagdad. Une partie des événements évoqués par Ibn al-Bannā', d'interprétation difficile aux yeux du lecteur moderne (émeutes populaires contre des prédicateurs aš ${ }^{\prime}$ arites $^{6}$ bénéficiant de la protection seldjoukide, rivalité pour l'occupation des lieux prestigieux de la scène religieuse bagdadienne, opposition entre certaines personnalités hanbalites et les autres milieux religieux, voire rivalités internes au groupe hanbalite lui-même), sont à replacer dans ce contexte d'effervescence politique, sociale et religieuse dans lequel les hanbalites bagdadiens tentaient d'affirmer leur place au sein de la légitimité sunnite en cours de reconfiguration.

3. La première entrée à Bagdad du chef de guerre seldjoukide Ṭugril Beg date du mois de ramadan 447/novembre 1055; le calife abbasside al-Qā'im qui lui octroya officiellement le titre de sultan en dū l-qa'da 449/janvier 1058. Țugril Beg ayant quitté Bagdad en raison de ses propres impératifs militaires, son départ fut suivi d'une période de troubles au cours de laquelle un militaire turc, al-Basāsīrī, mamelouk du souverain bouyide Bahā’ al-dawla, prit le pouvoir à Bagdad et fit passer la ville sous obédience des Fatimides du Caire. Le calife abbasside, exilé pendant une année, ne put rentrer à Bagdad qu'avec l'aide de Ṭğril Beg, fin 451/1059.

4. Ṭugril Beg avait résidé plusieurs mois à Bagdad entre 447 et 452/1055-60, mais son successeur Alp Arslān ne se rendit pas une seule fois dans la capitale abbasside au cours de ses dix années de règne (455-65/1063-72).

5. C'est avec ces restrictions qu'il faut considérer la notion de « renaissance sunnite » (Sunni revival) traditionnellement assignée à la période seldjoukide.

6. L'aš‘arisme est l'une des branches de la théologie spéculative musulmane (kalām), à laquelle les hanbalites étaient fortement opposés. 
C'est aussi dans ce contexte qu'il faut replacer l'apparition à Bagdad des premières madrasas fondées par les dignitaires seldjoukides, et surtout l'absence totale de ces institutions sous la plume d'Ibn al-Bannā'. À l'époque de rédaction du « Journal », aucune des deux madrasas édifiées à Bagdad ne pouvait offrir d'opportunité professionnelle aux hanbalites : la madrasa Nizāmiyya (inaugurée en 459/1067) était réservée aux šăfi ites et la madrasa d'Abū Sa'd al-mustawfī (fondée la même année par un fonctionnaire de Malikšāh) aux hanafites. Les premières madrasas destinées aux hanbalites n'apparurent que plusieurs décennies plus tard ; pour les hanbalites bagdadiens, la seconde moitié $\mathrm{du} \mathrm{v}^{\mathrm{e}} / \mathrm{xl}^{\mathrm{e}}$ siècle est donc à considérer comme une période " pré-madrasas ", les bouleversements liés à l'instauration de postes rémunérés dans le domaine de la transmission du figh étant, pour eux, nettement postérieurs à l'époque de rédaction du «Journal ».

De par l'originalité de son contenu, le texte d'Ibn al-Bannā' met en lumière l'existence d'un réseau social que l'on peut qualifier de hanbalite, dans le sens où l'ensemble des membres le composant se réclamaient de l'affiliation à ce madhab, même pour ceux d'entre eux qui ne semblent pas s'être illustrés dans le domaine de l'étude, de la pratique ou de la transmission du droit musulman. L'intérêt du « Journal » est en effet d'accorder une place importante à des personnages en général absents des autres sources historiographiques et biographiques : de riches commerçants, membres actifs du groupe hanbalite dont ils étaient les mécènes.

\section{Les principaux acteurs du réseau hanbalite bagdadien}

Le «Journal » d'Ibn al-Bannā', d'une grande richesse prosopographique l'index établi par Makdisi recense plusieurs centaines de noms propres - est centré sur des relations de personne à personne. Plusieurs dizaines de personnages évoqués par le texte sont des contemporains de l'auteur, identifiables grâce à d'autres sources rédigées à la même époque ou postérieures (dictionnaires biographiques mais aussi chroniques retraçant l'histoire de Bagdad). Cependant, seuls une dizaine de personnages sont évoqués à plus de trois reprises chacun : il s'agit en premier lieu des grandes figures du groupe hanbalite auquel appartenait l'auteur', et qui pour la plupart résidaient dans le même quartier que lui, celui de Bāb al-marātib.

Le groupe hanbalite et ses activités occupent en effet une bonne partie du contenu du « Journal » : plus de la moitié des passages (plus de

7. On note cependant la présence, parmi les protagonistes les plus fréquemment évoqués par le « Journal », d'un faqīh šāfi ite (Ibn al-Ṣabbāğg, connu par d'autres sources biographiques et décédé en 477/1084) et d'un personnage de confession juive, Ibn Faḍlān al-Yahūdī, lié aux milieux du pouvoir. 
105 paragraphes sur 185) mettent en scène ses membres, dans leurs activités quotidiennes ou celles plus exceptionnelles qui étaient, dans la plupart des cas, des occasions de contact et d'action collective. Ce sont ces situations d'interaction sociale qui constituent la base de la présente étude du réseau constitué par les hanbalites bagdadiens de Bāb al-marātib, dont on peut repérer les personnalités les plus importantes en fonction du nombre de fois où elles sont mentionnées dans le « Journal ». Point remarquable, presque tous ces individus étaient de la génération exacte d'Ibn al-Bannā' qui, né en 396/1005, avait 64 ans à l'époque de rédaction des passages conservés du texte.

\section{Groupe hanbalite et réseau hanbalite}

Il faut préciser que les activités des individus décrits ci-dessous prenaient place au sein d'un ensemble doté d'une conscience collective fondée sur l'affiliation au madhab hanbalite, affiliation reposant, comme le souligne Daphna Ephrat dans son travail sur les ulémas bagdadiens du $\mathrm{V}^{\mathrm{e}} / \mathrm{XI}^{\mathrm{e}}$ siècle, moins sur l'étude et la pratique du fiqh hanbalite que sur le partage de postures morales et théologiques ${ }^{8}$; à savoir, donc, sur l'adhésion à un système de valeurs morales et leur défense dans le domaine des pratiques sociales. Établi sur ces bases, le groupe hanbalite avait une très grande cohésion ; ses membres se désignaient eux-mêmes sous le terme collectif de ğamā'a ("groupe, ensemble, réunion») et exprimaient régulièrement leur sentiment d'appartenance collective, fondé sur l'adhésion à ces valeurs communes ${ }^{9}$. On distinguera ici le groupe, à savoir l'ensemble des hanbalites individualisés ou anonymes régulièrement évoqués par Ibn al-Bannā’ (les « compagnons » hanbalites, șāhị pl. aṣhāab), du réseau à proprement parler, composé de personnages individualisés, entretenant chacun des liens avec une grande partie des autres acteurs, et dont l'intervention dans la vie du groupe était récurrente et discriminante en matière de résultats. Seuls les individus les plus fréquemment évoqués en situation d'interaction sociale avec d'autres hanbalites, eux aussi individualisés et fréquemment évoqués, sont ici considérés comme les acteurs du réseau, les « nœuds » autour desquels se tissent les ensembles de relations (« liens ») qui déterminent la configuration de ce réseau.

8. Voir D. Ephrat, A Learned Society in a Period of Transition - The Sunni 'Ulamā' of Eleventh-Century Baghdad, New York, 2000, en particulier le chapitre 4 ( « Forms of social affiliation»).

9. Sur ces aspects, voir V. Van Renterghem, « Le sentiment d'appartenance collective chez les élites bagdadiennes des $\mathrm{V}^{\mathrm{e}}-\mathrm{VI}^{e} / \mathrm{XI}^{\mathrm{e}}$-XII ${ }^{e}$ siècles », Annales islamologiques 42, 2008, p. 231-258. 


\section{Abū 'Alī ibn al-Bannā'}

Le personnage le plus présent dans le « Journal » est bien entendu son auteur lui-même, puisque le texte consigne en priorité ses activités et qu'il apparaît donc en personne, comme acteur ou témoin des événements, dans plus de la moitié des paragraphes; bien logiquement, il occupe en conséquence une place centrale dans l'interaction avec les autres membres du réseau hanbalite. L'importance de son rôle effectif au sein de ce réseau est cependant confirmée par la longueur des notices qui lui sont consacrées dans les dictionnaires biographiques postérieurs ${ }^{10}$. Le « Journal » le met en scène dans des activités liées à l'élaboration et à la transmission du savoir traditionnel (fiqh, coran, hadīt) ou répondant à des obligations sociales et religieuses (sociabilité de voisinage, fonction d'autorité religieuse). En regard des relations denses et nourries qu'il entretenait avec les membres du groupe hanbalite $e^{11}$, ses relations avec ses contemporains non hanbalites et avec les milieux du pouvoir apparaissent relativement peu nombreuses et dans l'ensemble mauvaises ${ }^{12}$, caractérisées par l'affrontement ou la condamnation.

\section{Le šarīf Abū Ğa'far ibn Abī Mūsā, charismatique et controversé}

Le deuxième personnage le plus fréquemment évoqué par Ibn al-Bannā'13 était un hanbalite charismatique, jouant du prestige de son ascendance hashimite, le šarīf Abū Ğa'far ibn Abī Mūsā. Sensiblement plus jeune qu'Ibn al-Bannā' et que les autres hanbalites occupant une place importante dans le « Journal », le šarîf Abū Ğa'far, né en 411/1020, avait 49 ans à l'époque des faits; il mourut à peu près en même temps qu'Ibn al-Bannā', en 470/1077. Il s'agit, à l'égal d'Ibn al-Bannā', d'un personnage bien documenté par les sources biographiques ${ }^{14}$. Hanbalite

10. Une dizaine d'ouvrages historiographiques ou biographiques consacrent une notice à Abū 'Alī ibn al-Bannā'. Les principaux sont Ibn Abī Ya'lā (m. 526/1132), Ṭabaqāt al-ḥanābila, éd. Abū Hāzim Usāma b. Hasan et Abū l-Zahrā' Hāzim 'Alī Bahğat, Beyrouth, 1999, t. 2, p. 208, notice $n^{\circ} 677$; Ibn al-Ğawzī, al-Muntazăam, op. cit., t. 16, p. 200, notice n 3485 ; Yāqūt al-Hamawī (m. 626/1229), Mu 'ğam al-udabā', Beyrouth, 1991, t. 2, p. 329, notice n 303 ; Ibn Rağab (m. 795/1392), Dayyl 'alā țabaqāt al-ḥanābila, éd. Abū Hāzim Usāma b. Ḥasan et Abū l-Zahrā' Hāzim 'Alī Bahğat, Beyrouth, 1999, t. 3, p. 27, notice n 14 ; Ibn al-'Imād (m. 1089/1678), Šadarāt al-ḍahab, éd. 'Abd al-Qādir et Maḥmūd al-Arnā’ūț, Damas-Beyrouth, 1989 , t. 5 , p. 306.

11. 89 situations d'interaction sociale d'Ibn al-Bannā' avec d'autres hanbalites sont évoquées par le « Journal ».

12. En dehors d'interactions ponctuelles avec des ulémas d'affiliation non hanbalite, comme la séance évoquée au § 98, où Ibn al-Bannā’ rapporte avoir cordialement débattu de la question des ablutions avec son collègue šāfi ite Abū Nașr ibn al-Șabbāğ.

13. Trente-trois situations recensées d'interaction sociale avec d'autres hanbalites.

14. Voir notamment Ibn al-Ğawzī, al-Muntazam, op. cit., t. 16, p. 195, notice n 3482 ; 
rigoriste et haut en verbe, versé dans toutes les branches du savoir traditionnel, il connut à plusieurs reprises des démêlés avec les autorités califales et sultaniennes; le « Journal » en relate de nombreux épisodes, y compris celui de la période de disgrâce au cours de laquelle il fut assigné à résidence au sein des quartiers califaux. Réputé pour son ascétisme et son dédain des richesses matérielles, le šarîf Abū Ğa'far pouvait compter sur le soutien inconditionnel d'un groupe de partisans hanbalites, parmi lesquels figurait Ibn al-Bannā', mais entretenait des relations complexes avec certains notables du groupe, et notamment avec les commerçants-mécènes qui sont les deux autres personnages centraux du « Journal $»^{15}$.

\section{Ibn Ğarada, riche commerçant et mécène}

Contrairement aux lettrés présentés jusqu'ici, ce commerçant, au statut matériel élevé (les indices de sa grande richesse sont nombreux dans le « Journal »), tout comme Abū l-Qāsim ibn Rị̣̂ān présenté plus loin, est à peine évoqué dans les autres sources historiographiques, qui lui consacrent au mieux quelques lignes ${ }^{16}$. Ibn Ğarada était pourtant l'un des personnages centraux du réseau hanbalite (25 situations d'interaction sociale avec les autres hanbalites sont mentionnées en ce qui le concerne). Du même âge qu'Ibn al-Bannā' ${ }^{\prime 17}$, il possédait une immense résidence dans le quartier de Bāb al-marātib ${ }^{18}$, et Ibn al-Ğawzī estime son patrimoine à plus de 300000 dinars, somme colossale qui faisait de lui l'un des hommes les plus fortunés de Bagdad à son époque ${ }^{19}$. Cette fortune avait été bâtie sur des

Ibn Abī Ya'lā, Ṭabaqāt al-hanāōila, op. cit., t. 2, p. 203, notice nº 674 ; Ibn Rağab, Dayl, op. cit., t. 3, p. 13, notice n' 11 ; Ibn al-'Imād, Šadarāt al-d̆ahab, op. cit., t. 5, p. 302.

15. L'appartenance au madhab de ces commerçants, et en particulier d'Ibn Ğarada, pour lequel aucune connaissance particulière en matière de science traditionnelle n'est soulignée, doit être comprise, comme précisé plus haut, moins en termes d'affiliation à une école de droit que d'adhésion à un système de valeurs morales, doublée d'une inclusion sociale forte dans un groupe dont ces commerçants étaient les financiers et mécènes.

16. Cela s'explique bien logiquement par le fait que les sources biographiques ont pour objectif premier de décrire les milieux responsables de l'élaboration et de la transmission du savoir traditionnel, champ d'activité auquel ces deux commerçants ne participaient qu'indirectement, par leur rôle de mécènes.

17. Né en 395/1004 et décédé en 476/1084. Voir aussi Ibn al-Dubayțī (m. 637/1239), Dayl ta'rīh madīnat al-salām Baġdād, éd. Baššār 'Awwād Ma'rūf, Bagdad, 1974, t. 1, p. 80, notice n’ 2.

18. Cette résidence se composait de trente bâtiments distincts, et comprenait des jardins ou vergers (bustān), un hammam et deux oratoires (masğid-s). Voir la notice d'Ibn Ğarada chez Ibn al-Ğawzī, al-Muntazam, op. cit., t. 16, p. 232, notice n 3531.

19. Ibid. Revenus et patrimoines des notables bagdadiens sont rarement détaillés par les sources, mais à titre de comparaison, on peut citer les 600000 dinars possédés par le vizir du calife Abū Šuğā‘ avant sa destitution en 484/1091 (chiffre donné par Sibṭ ibn al-Ğawzī 
activités commerciales, même si le détail de celles-ci n'est pas connu; les sources qualifient Ibn Ğarada de «commerçant » (al-bayyi'), évoquent ses nombreuses aumônes en faveur des pauvres et laissent entrevoir qu'il était proche des milieux du pouvoir ${ }^{20}$. Par égard envers son haut statut social, ses contemporains le désignaient sous le titre honorifique de «très honorable shaykh » (al-šayḩ al-ă̆all).

\section{Abū l-Qāsim ibn Riḍwān, commerçant et témoin instrumentaire}

Le second grand commerçant hanbalite, Abū l-Qāsim ibn Riḍwān (21 situations d'interaction avec des hanbalites mentionnées dans le «Journal »), devait avoir quelques connaissances en fiqh puisqu'il officiait en tant que témoin instrumentaire ( $̌$ āhid) ; mais sa fortune provenait certainement de ses activités commerciales, elles aussi attestées bien que mal connues ${ }^{21}$. Là encore, le récit de ses aumônes est fréquent, et ses liens avec les milieux du pouvoir sont bien documentés : en 467/1075 on le retrouve, aux côtés de son confrère Ibn Ğarada, parmi les notables convoqués pour faire la bay'a (serment d'allégeance) au nom du nouveau calife al-Muqtadī, et le «Journal» témoigne du fait qu'il avait un accès direct au calife ${ }^{22}$, privilège réservé à un nombre limité de notables bagdadiens. Plusieurs épisodes évoquent son pouvoir d'intercession auprès des milieux califaux, au profit d'habitants de son quartier ou de ses compagnons hanbalites. Par la suite, il établit aussi des liens avec les milieux seldjoukides, notamment en donnant sa fille en mariage au fils du célèbre vizir Niz̄ām al-mulk, Mu'ayyad al-mulk ${ }^{23}$. Lui-même avait épousé une fille d'un autre notable hanbalite, décédé à l'époque de rédaction du "Journal», Abū Manșūr ibn Yūsuf. Il était ainsi indirectement allié à Ibn Ğarada, qui avait lui aussi épousé l'une des filles d'Abū Manșūr.

(m. 654/1256), Mir'āt al-zamān, éd. Musfir b. Sālim b. 'Arī̌̆ al-Ġāmirī, La Mecque, 1987, t. 1, p. 258).

20. Lors de la révolte d'al-Basāsīrī contre le pouvoir abbasside et seldjoukide, Ibn Ğarada abrita dans son palais la nièce du sultan Ṭuggril Beg, qui avait épousé le calife al-Qā’im ; il en fut remercié par le sultan. On retrouve aussi Ibn Ğarada parmi les notables prêtant serment d'allégeance (la bay'a) auprès du nouveau calife al-Muqtadī, après la mort de son prédécesseur al-Qā’im, en 467/1075 (Ibn al-Ğawzī, al-Muntazam, op. cit., t. 16, p. 163).

21. Le « Journal » évoque un associé d'Ibn Ridwān ayant fait naufrage au cours d'un voyage vers Mossoul, à bord d'un navire chargé de marchandises (§ 145); il parle aussi d'un caravansérail (hān) où Ibn Riḍwān entreposait ses marchandises, dans lequel une inondation causa d'importants dégâts (\$120).

22 . $\$ 68:$ Ibn Riḍān est convoqué par le calife qui souhaite lui remettre une robe d'honneur en signe de congratulation pour sa santé recouvrée après une maladie.

23. En 466/1074. Ibn al-Ğawzī, al-Muntazam, op. cit., t. 16, p. 157. 


\begin{abstract}
Abū Manșūr ibn Yūsuf, le «très honorable shaykh » (al-šayh al-ağall) Bien que décédé peu de temps avant le début des passages conservés du «Journal », en 460/1067, Abū Manșūr ibn Yūsuf ${ }^{24}$ est l'un des personnages centraux du texte d'Ibn al-Bannā', soit qu'il apparaisse en rêve à ses contemporains, soit que ceux-ci aillent visiter sa tombe pour recueillir sa baraka posthume, soit enfin que ses fils soient mentionnés comme trace de la continuité de la présence de leur père dans la société des vivants ${ }^{25}$. Il faut ainsi considérer ce défunt comme l'un des acteurs effectifs du réseau hanbalite, la mort physique d'un membre n'engendrant pas sa disparition immédiate du réseau. Né lui aussi en 395/1004, Abū Manșūr ibn Yūsuf avait, de son vivant, porté le titre de «très honorable shaykh » (al-šayh al-ağall) attribué par la suite à Ibn Ğarada. Versé en hadīt, il était à la tête d'un patrimoine non négligeable (ses fils héritèrent à sa mort de 30000 dinars en biens immobiliers ${ }^{26}$ ) qui lui permettait libéralités et aumônes au sein de son groupe mais aussi en dehors ; les Bagdadiens lui devaient notamment la rénovation de l'hôpital fondé par le souverain bouyide 'Aḍud al-dawla, le Bīmāristān al-'Aḍudī, situé au nord de la rive occidentale du Tigre ${ }^{27}$.

Ces cinq personnages (Abū 'Alī ibn al-Bannā', le šarīf Abū Ğa'far ibn Abī Mūsā, le šayh al-ağall Ibn Ğarada, Abū l-Qāsim ibn Riḍwān et le défunt Abū Manșūr ibn Yūsuf) étaient les acteurs les plus importants du réseau hanbalite tel qu'il nous est donné à voir à travers le «Journal »; il faut leur ajouter quatre autres hanbalites d'importance secondaire, mais qui jouaient cependant un rôle certain dans l'organisation du réseau.
\end{abstract}

'Abdallāh al-Baradānī, ascète hanbalite de la rive occidentale de Bagdad Le premier était un ascète ( $z$ āhid) nommé 'Abdallāh al-Baradānī ${ }^{28}$, vivant retiré dans une habitation du quartier de Dār al-Qatțān sur la rive

24. Voir l'assez longue notice que lui consacre Ibn al-Ğawzī, al-Muntazam, op. cit., t. 16, p. 107, notice $n^{\circ} 3394$, ainsi que les mentions de ce personnage chez al-Hațīb al-Baġdādī (m. 463/1071), Ta'rīh Bag̀dād aw madīnat al-salām, éd. Mușțafā 'Abd al-Qādir 'Ațā, Beyrouth, 1997, t. 10, p. 433, notice $n^{\circ} 5599$; al-Bundārī (milieu du vII $/$ XIII $^{\mathrm{e}}$ siècle), Ta'rīh dawlat âl Salğūq (Zubdat al-nușra wa nuhbat al-'ușra), Beyrouth, 1980³, p. 35 ; Ibn Kațīr (m. 774/1373), al-Bidāya wa l-nihāya, éd. Ahmad 'Abd al-Wahhāb Fatīh, Le Caire, 1994, t. 12, p. 105.

25. Sous ces trois modalités, Abū Manșūr ibn Yūsuf apparaît à 15 reprises dans le « Journal » en situation d'interaction posthume avec d'autres hanbalites.

26. Ibn al-Ğawzī, al-Muntaz̧am, op. cit., t. 16, p. 107, notice $n^{\circ} 3394$, et Ibn al-Bannā', « Journal », § 88 .

27. Ibn al-Ațīr (m. 630/1232), al-Kāmil fì l-ta'rīhn, éd. Muhammad Yūsuf al-Daqqāq, Beyrouth, 1998, t. 8, p. 381, et al-Bundārī, Zubda, op. cit., p. 35.

28. Mort en 461/1069, 12 occasions d'interaction avec d'autres hanbalites dans le « Journal ». On trouvera une notice consacrée à al-Baradānī chez Ibn Rağab, Dayl, op. cit., t. 3, p. 6, notice $n^{\circ} 4$. 
occidentale de Bagdad. Ibn al-Bannā' mentionne à plusieurs reprises les visites qu'il lui rendait ${ }^{29}$; à l'occasion de l'une d'elles, il lui demanda de prier pour le rétablissement d'Abū l-Qāsim ibn Riḍwān, frappé de maladie. Il décrit également les funérailles de l'ascète ${ }^{30}$, suivies par une foule imposante, à la principale mosquée de la rive occidentale, Ğāmi ${ }^{\prime}$ al-Manșūr ; le corps fut lavé par le šarîf Abū Ğa'far, tandis qu'Ibn Ğarada et Ibn Riḍ̂ān avaient pourvu au linceul et à tout le nécessaire pour les funérailles, al-Baradānī se trouvant dans une situation de grand dénuement matériel.

\section{Le šaríf Ibn Sukkara, activiste des bonnes mœurs}

Le second était un hashimite du nom d'Abū 'Alī ibn Sukkara; les sources biographiques sont silencieuses à son propos, mais quelques courtes mentions dans les chroniques et dans le « Journal » permettent de le classer sans hésitation parmi les activistes hanbalites ${ }^{31}$, à l'instar du šarif Abū Ğa'far ibn Abī Mūsā, bien qu'Ibn Sukkara apparaisse comme un personnage moins important que ce dernier ; tout comme Abū Ğa'far, on le trouve en contact avec les milieux du pouvoir ainsi qu'avec les nonhanbalites. Si l'on en croit son propre témoignage, Ibn al-Bannā' entretenait des relations suivies avec Ibn Sukkara.

\section{Ibn 'Aqïl, un hanbalite dissident ?}

Les deux derniers acteurs du réseau hanbalite à apparaitre régulièrement dans le « Journal » se trouvaient dans une situation moins centrale que les personnages précédents; l'un en raison de la rupture intellectuelle qui l'opposait à la majorité des membres du groupe, l'autre pour des raisons moins évidentes. Le premier était le célèbre Abū l-Wafā' ibn 'Aqīl. Né en $431 / 1040$, il était sensiblement plus jeune que les autres personnages évoqués plus haut, tous nés dans les dernières années $\mathrm{du} I \mathrm{IV}^{\mathrm{e}} / \mathrm{x}^{\mathrm{e}}$ siècle ou les premières $\mathrm{du} \mathrm{v} / \mathrm{vI}^{\mathrm{e}}$. Versé dans les matières traditionnelles et affilié au madhab hanbalite en matière de fiqh - discipline qu'il avait étudiée auprès de l'illustre Abū Ya'lāi ibn al-Farrā’' (m. 458/1066), son intérêt pour le courant

\footnotetext{
29. Par exemple § 25 et 63.

$30 . \S 66$ et 67 .

31. On le voit ainsi briser des jarres de vin appartenant à l'émir al-Basāsīrī en 447/1055 (Ibn al-Ațīr, al-Kāmil, op. cit., t. 8, p. 321), lutter pour le rétablissement de l'obligation du port du signe distinctif pour les dimmī-s en 450/1058 (Ibn al-Ğawzī, al-Muntazam, op. cit., t. 16, p. 30), s'opposer au prédicateur aš'arite Ilkyā al-Harrāsī en 461/1067 (Ibn al-Bannā', « Journal », § 57) puis lutter contre la consommation de vin dans les quartiers califaux (Ibid., § 108) et proclamer l'obligation de briser les intruments de musique (Ibid., § 110 et $111)$.
} 
de pensée mu'tazilite en matière de théologie dogmatique (kalām) lui valut l'ostracisme de la majeure partie des membres bagdadiens de son madhab. À l'époque de rédaction des fragments conservés du « Journal », Ibn 'Aqīl, considéré comme un renégat à la cause hanbalite, était littéralement banni de son groupe; Ibn al-Bannā' exprime bien la répugnance extrême dont ses anciens compagnons firent preuve envers lui. Il est donc logique que dans le « Journal » son rôle au sein du réseau hanbalite soit réduit et marginal (6 occasions d'interaction avec d'autres hanbalites seulement; ses relations avec Ibn al-Bannā' et le šarîf Abū Ğa'far étaient, à l'époque, des plus mauvaises). Quelques années plus tard, en 465/1072, Ibn 'Aqīl fit publiquement acte de contrition et se réconcilia avec le šarîf Abū Ğa'far, son adversaire le plus intransigeant; il retrouva ainsi une place au sein des milieux hanbalites. Il mourut en 513/111932.

\section{Abū Muhammad al-Tamīmī, un notable outsider?}

Il est par contre moins évident de comprendre pourquoi l'un des derniers acteurs du réseau hanbalite, le 'ālim et faqīh Abū Muhammad al-Tamīmī, se trouve lui aussi en situation marginale: alors que ce personnage est très bien documenté dans les sources biographiques, le « Journal » le présente comme n'ayant entretenu de liens directs qu'avec deux autres membres du réseau, Ibn Sukkara et le šarîf Abū Ğa'far, Ibn al-Bannā' lui-même n'entrant jamais directement en contact avec lui ${ }^{33}$. Né entre 396 et 401/1005-11 selon ses biographes, Abū Muhammad al-Tamīmī était du même âge qu'Ibn al-Bannā', le šarîf Abū Ğa 'far, Ibn Ğarada et Abū Manșūr ibn Yūsuf; il mourut en $488 / 1095^{34}$. Spécialiste de sciences traditionnelles (coran, figh, hadīt) et littéraires, il prêchait le $w a z^{35}$ et enseignait le fiqh, à la Ğāmi' al-Manșūr (sur la rive occidentale de Bagdad) puis à la Ğāmi ${ }^{\circ}$

32. Sur Ibn 'Aqīl, voir notamment Ibn al-Ğawzī, al-Muntazam, op. cit., t. 17, p. 179, notice n 3882 ; Sibṭ ibn al-Ğawzī, Mir'āt, op. cit., t. 2, p. 691; Ibn al-Dimyāțī (m. 749/1348), al-Mustafād min dayl ta'rịh Baġdād, éd. Muștafā 'Abd al-Qādir 'Ațā, Beyrouth, 1997, t. 21, p. 145, notice n` 147 ; Ibn Rağab, Dayl, op. cit., t. 3, p. 118, notice n' 66 ; Ibn al-'Imād, Šadarāt al-dahab, op. cit., t. 6, p. 58-62. Pour une analyse de l'« affaire Ibn 'Aqīl », voir G. Makdisi, Ibn 'Aqïl et la résurgence de l'islam traditionaliste au XI siècle ( $V^{e}$ siècle de l'Hégire), Damas, 1963.

33. En tout, 7 occasions d'interaction avec d'autres hanbalites sont imputées à ce personnage.

34. Voir les notices biographiques que lui consacrent Ibn Abī Ya'lā, Ṭabaqāt al-hanāäbila, op. cit., t. 2, p. 214, notice $n^{\circ} 687$; Ibn al-Ğawzī, al-Muntazam, op. cit., t. 17, p. 19, notice n 3650 ; Sibṭ ibn al-Ğawzī, Mir'āt, op. cit., t. 1, p. 249 ; Yāqūt, Mu ‘̆gam al-udabā', op. cit., t. 3, p. 334, notice $n^{\circ} 419$; Ibn al-Dimyāțī, Mustafād, op. cit., t. 21, p. 85, notice nº 77 ; Ibn Rağab, Dayl, op. cit., t. 3, p. 64, notice n 31 ; Ibn al-'Imād, Šadarāt al-dahab, op. cit., t. 5, p. 380.

35. Forme de prédication populaire donnant l'occasion aux prédicateurs (wā'iz, pl. wu' $\bar{a} z$ ) d'exprimer publiquement leurs opinions théologiques. 
al-Qașr, la mosquée des palais califaux sur la rive orientale, et s'était lui aussi installé dans le quartier de Bāb al-marātib. Un grand nombre de disciples lui sont connus, parmi lesquels on retrouve Ibn 'Aqīl et Ibn Sukkara. Il officiait également comme témoin instrumentaire (šāhid) et fut chargé par les califes abbassides de plusieurs missions diplomatiques auprès des sultans seldjoukides. Enfin, le « Journal » témoigne à plusieurs reprises de son implication dans la sociabilité des hanbalites de Bāb al-marātib ${ }^{36}$. Il est donc difficile d'interpréter le peu de relations de ce personnage avec les autres acteurs influents du réseau hanbalite : soit que ses activités au sein des milieux du pouvoir aient été trop accaparantes pour lui laisser le temps de rencontrer ses compagnons de madhab ; soit et cela est peut-être plus vraisemblable - qu'une inimitié ou une rivalité personnelle ait poussé Ibn al-Bannā' à minimiser le rôle d'al-Tamīmī, 'ālim d'envergure susceptible de rivaliser avec lui, dans le milieu des hanbalites de Bāb al-marātib.

\section{La construction du réseau :}

\section{activités et situations d'interaction sociale}

On peut distinguer plusieurs types de liens établis entre les acteurs principaux du réseau hanbalite: certains, comme les relations de voisinage et les liens établis au cours de l'exercice d'une activité précise (accomplissement des rites religieux, transmission du savoir traditionnel), pouvaient être partagés avec d'autres membres du groupe hanbalite; d'autres, comme les relations matrimoniales et les relations de mécénat, renforçaient les liaisons plus exclusives entre les différents acteurs du seul réseau.

\section{Relations de voisinage}

Les relations de voisinage, répondant aux obligations d'une sociabilité de quartier, sont omniprésentes dans le « Journal » et constituent une bonne partie des occupations quotidiennes d'Ibn al-Bannā', sous la forme de visites occasionnelles au domicile privé des personnes (nécessaires en cas de naissance et surtout de décès dans le groupe hanbalite) et de réunions collectives en d'autres occasions (mariages), dont certaines se déroulaient au domicile des commerçants-mécènes. Il est difficile de faire la part, dans ce domaine, de la sociabilité de quartier et de celle reposant sur l'appartenance au groupe hanbalite, tant l'homogénéité en la matière du quartier de Bāb al-marātib semble avoir été grande ; on peut cependant

36. § 99 : il assure publiquement le šarîf $A b \bar{u} \breve{G} a$ far de son soutien; § 113 : il appuie Ibn Sukkara contre les accusations des šăfi ites; $§ 199$ et 135 : il dirige la prière funéraire en l'honneur de hanbalites défunts, etc. 
supposer que les obligations découlant de l'affiliation à un même madhab étaient plus fortes encore que la simple communauté de résidence car, à plusieurs reprises, Ibn al-Bannā' se déplaça hors de son quartier pour rendre visite à des compagnons hanbalites résidant dans d'autres secteurs de Bagdad.

\section{La pratique religieuse collective et le travail des autorités religieuses}

D'autres occasions de rencontre des principaux acteurs du réseau hanbalite découlaient des obligations collectives de la pratique religieuse : prière en commun du vendredi, mais aussi assistance aux cérémonies funéraires en cas de décès d'un membre, visites régulières aux tombes des principaux défunts, assorties de récitations coraniques, etc., ainsi que des modalités de la transmission du savoir traditionnel. Si les premières engendraient des réunions du groupe ou au moins de certains de ses membres, l'enseignement des matières religieuses et juridiques (coran, hadit, figh) permettait de créer et de renforcer des liens individuels entre le maître et ses disciples, mais aussi entre disciples d'un maitre commun, et même entre maîtres et mécènes, dans le cas de cours « privés » délivrés par les lettrés hanbalites aux enfants des grands commerçants ou à d'autres lettrés et dans le cas de financement d'institutions d'enseignement par ces mécènes.

\section{Les activités liées à la transmission du savoir}

Les liens établis entre disciples d'un maitre commun ont pu jouer un rôle d'autant plus important que les principaux lettrés membres du réseau hanbalite étaient de la même génération, et s'étaient donc sans doute côtoyés dès leur période de formation ${ }^{37}$ dans les cercles d'études (halqa, mağlis) des ulémas de leur temps. L'examen de leurs listes de maîtres le confirme. Ibn al-Bannā', le šarîf Abū Ğa'far et Abū Muhammad al-Tamīmī avaient tous trois suivi l'enseignement des principaux ulémas bagdadiens de la première moitié $\mathrm{du} \mathrm{v}^{\mathrm{e}} / \mathrm{xI}^{\mathrm{e}}$ siècle : les célèbres transmetteurs de hadit Abū l-Husayn et Abū l-Qāsim ibn Bišrān, et le grand maître de figh hanbalite Abū Ya'lā ibn al-Farrā' (m. 458/1066) (38 $^{38}$ Ibn 'Aqīl fut aussi le disciple

37. Cette période de formation pouvait être longue : les jeunes enfants étaient parfois mis à l'étude par leur père avant d'avoir dix ans, et Ibn al-Ğawzī lui-même recommandait d'étudier jusqu'à l'âge de quarante ans avant de se mettre à produire des ouvrages. Șayd al-Huatir (la pensée vigile), trad. fr. D. Reig, Paris, 1986, § 102, p. 212.

38. Voir l'imposante notice que lui consacre son fils Ibn Abī Ya'lā, Ṭabaqāt al-ḥanābila, op. cit., t. 2, p. 166-185. Dans la longue liste de ses disciples de fiqh et de hadīt, on rencontre de nombreux hanbalites évoqués par le «Journal ", ainsi que deux fils d'Abū Manșūr b. Yūsuf et deux fils d'Ibn Riḍwān. 
d'Ibn al-Farrā', probablement plus tard en raison du décalage générationnel, et apprit le hadīt de la bouche d'Abū Bakr ibn Bišrān, fils d'Abū l-Qāsim. Par ailleurs, Ibn al-Bannā' et Abū Muhammad al-Tamīmī avaient au moins deux autres maîtres en commun ${ }^{39} ;$ Ibn al-Bannā' avait aussi étudié auprès du père d'Abū Muhammad al-Tamīmī, Abū l-Faḍl, et de son oncle Abū l-Farağ ; Ibn 'Aqīl fut à son tour le disciple d'Abū Muhammad, et suivit l'enseignement de hadīt d'Abū Ṭālib al-'Ušārī (m. 451/1059), tout comme le šarîf Abū Ğa'far lui-même. De façon générale, le réseau de relations d'enseignement (liens de maître à disciples ou liens entre disciples d'un même maître) était particulièrement dense dans le milieu hanbalite, en raison du petit nombre de ses membres mais aussi de son caractère très fortement local, induisant une plus faible circulation géographique que dans les milieux šāfi' ites ou hanafites de Bagdad.

Une fois formé, le lettré pouvait à son tour enseigner. Ibn al-Bannā' lui-même illustre bien la diversité des liens créés à l'occasion d'activités de transmission du savoir traditionnel. Il avait un cercle d'étude (halqa) à la mosquée du palais califal, Ğāmi' al-Qașr, et un autre à Ğāmi' al-Manșūr, sur la rive occidentale ${ }^{40}$; il tenait aussi des séances publiques de coran, figh et hadīt dans l'oratoire (masğid) que lui avait octroyé Ibn Ğarada ${ }^{41}$ (ce qui suppose sans doute une rémunération, contrairement à son enseignement à Ğāmi' al-Manșūr et Ğāmi‘ al-Qașr). Mais le "Journal » le présente également dans des activités d'enseignement privé, donnant des cours particuliers de coran, hadīt et farā’id (calcul des parts d'héritage) au fils de son compagnon hanbalite Abū l-Ġanā'im $b$. Wăfā" ${ }^{42}$ et enseignant à l'un des fils d'Abū Manșūr ibn Yūsuf ${ }^{43}$. Les leçons aux fils étaient aussi une occasion de rencontrer les pères, et renforçaient les liens établis avec eux par Ibn al-Bannā'. Dans certains cas (enseignement des lettrés aux enfants de riches marchands non lettrés, dont on peut penser qu'il était rémunéré), les activités de transmission du savoir bénéficiaient du mécénat exercé par les commerçants hanbalites envers les membres moins fortunés de leur groupe.

39. Abū 'Alī ibn Abī Mūsā, oncle du šarîf Abū Ğa'far, en fiqh et Abū l-Ḥasan al-Ḥamāmī en coran et hadịt.

40. Ibn al-Ğawzī, al-Muntazam, op. cit., t. 16, p. 200, notice n 3485, et Ibn Abī Ya'lā, Tabaqāt al-hanābila, op. cit., t. 2, p. 208, notice n 677. Le « Journal » signale des séances semblables, notamment de figh, tenues par le šarīf Abū Ğa ‘far (\$ 85 et 98).

41. « Journal », § 35 .

42. Personnage non identifié par ailleurs; voir le § 113.

43. § 29. 


\section{Les activités de mécénat des riches marchands hanbalites}

Ces activités sont évoquées à maintes reprises dans le «Journal». Elles s'adressaient à divers niveaux de la sphère sociale, de l'aumône ponctuelle à un hanbalite nécessiteux au financement d'institutions destinées à durer dans l'espace urbain. L'aumône se faisait parfois collectivement, à l'occasion d'une réjouissance commune (fête religieuse ${ }^{44}$ ) ou ponctuelle (aumônes propitiatoires ou de remerciement, pour obtenir ou célébrer le rétablissement de l'état de santé du donateur, par exemple ${ }^{45}$ ), ou répondait parfois à la sollicitation d'un hanbalite indigent auprès des donateurs ${ }^{46}$. Certains dons étaient réguliers (annuels ou mensuels par exemple), et mettaient le receveur dans une position de dépendance envers le donneur, qui pouvait décider de les interrompre ; la mort du donateur pouvait aussi mettre fin à la subvention $^{47}$. La grande fortune d'Ibn Ğarada lui permettait aussi de jouer un rôle de protecteur envers ses compagnons en cas de crise politique ${ }^{48}$. Enfin, dans certains cas exceptionnels, la solidarité financière des hanbalites en faveur du groupe débordait la seule générosité des marchands-mécènes ${ }^{49}$.

Les plus riches hanbalites encourageaient aussi financièrement la sociabilité des membres de leur groupe en organisant à leurs domiciles

44. Les larges aumônes offertes aux pauvres bagdadiens par Ibn Ğarada à l'occasion des fêtes de fin de ramadan en 456/1064 dégénérèrent en émeute, occasionnant neuf morts ; il avait fait remettre à 200 pauvres une chemise et deux dirhams chacun (Ibn al-Ğawzī, al-Muntazam, op. cit., t. 16, p. 88).

45. «Journal », § 63 et 65 : Ibn Riḍwān fait distribuer de la viande (22 bovins sont égorgés pour l'occasion), du pain, des vêtements et de l'argent (2300 dirhams seldjoukides) pour célébrer son rétablissement. $§ 68$ : au cours de sa maladie, il avait dépensé 1000 dinars en aumônes en espérant recouvrer la santé. $§ 81$ : tombé malade, Ibn Ğarada fait des aumônes pour la même raison.

46. § 154 : un gulām malade et dans le besoin sollicite à deux reprises Ibn Riḍwān, dont il obtient dix dinars. Dans un cas extrême, les marchands hanbalites prennent à leur charge les frais des funérailles d'un ascète indigent (\$ 66), allant jusqu'à payer son linceul.

47. Le § 101 relate le cas d'un dénommé Abū l-Qāsim al-Dabbās, qui recevait périodiquement une aumône conséquente d'Abū Manșūr ibn Yūsuf par le truchement d'un intermédiaire. Après la mort d'Abū Manșūr, l'intermédiaire ayant refusé de lui octroyer la même somme, al-Dabbās se rendit sur la tombe du défunt pour solliciter son intercession, et trouva miraculeusement la somme qu'il attendait. Cette anecdote, qui a tout du topos, illustre bien la présence posthume des morts dans la société des vivants, permettant ici la poursuite du patronage privé d'Abū Manșūr en faveur d'al-Dabbās.

48. C'est ce qui se produisit lors de la rébellion d'al-Basāsīrī et des troubles qui la suivirent: Ibn Ğarada fit protéger sa résidence contre la somme de 10000 dinars, et y abrita ses collègues commerçants (tuğğār) ainsi garantis contre les pillages ; c'est également à Ibn Ğarada que fut confiée, lors des mêmes épisodes, la sécurité de la femme d'al-Qā'im et nièce du sultan seldjoukide Ṭuğril Beg (Ibn al-Ğawzī, al-Muntazam, op. cit., t. 16, p. 34).

49. § 83 : Ibn Ğarada et Ibn al-Bannā' envoient des dinars à leurs compagnons hanbalites impliqués, avec le šarîf Abū Ğa'far, dans une émeute ayant dégénéré, et retenus au dīwān califal. 
des cérémonies et des fêtes pour les occasions sociales comme les mariages ${ }^{50}$; certaines célébrations étaient l'occasion de dépenses ostentatoires, rappelant à la fois leur grande richesse et leur position de mécènes de leur communauté ${ }^{51}$.

Le plus fortuné des hanbalites, Ibn Ğarada, se fit même bâtisseur : les sources biographiques lui attribuent la construction d'un oratoire (masğid) portant son nom, celui-là même où enseignait Ibn al-Bannā', à Nahr al-Mu'allā (sur la rive orientale de Bagdad, au nord des quartiers califaux) ${ }^{52}$. Ce masğid continua à exister bien après la mort de son fondateur, bien qu'il ait été ravagé par un incendie en $485 / 1092^{53}$, et l'on connait le nom des lettrés qui y enseignèrent jusqu'au milieu $\mathrm{du} \mathrm{vI} / \mathrm{XII}^{\mathrm{e}}$ siècle ${ }^{54}$. L'oratoire demeura un lieu de forte présence hanbalite hors du quartier de Bāb al-marātib : les enseignants y étaient hanbalites et, à plusieurs reprises, l'endroit fut le théâtre d'affrontements entre partisans du madhab d'Ahmad ibn Hanbal et prédicateurs aš arites soutenus par les Seldjoukides ${ }^{55}$.

Par leur soutien matériel aux activités des ulémas de leur groupe, autant que par la sociabilité qui les liait à ces derniers, les grands marchands hanbalites se rattachaient à l'univers des lettrés, sans en faire directement partie. La coopération entre riches commerçants et ulémas hanbalites peut s'interpréter comme une modalité de circulation réciproque de la richesse des uns et du prestige attaché à l'exercice des fonctions intellectuelles et religieuses des autres. La proximité sociale entre ces deux milieux était renforcée par des alliances matrimoniales aux enjeux souvent multiples.

50. Mentions d'un mariage unissant deux familles de commerçants se déroulant au domicile d'Ibn Ridwān (§ 134) et d'un autre se tenant chez Ibn Ğarada (§ 175).

51. $\$ 45$ : les fils d'Abū Manșūr ibn Yūsuf organisent une réception ( $d a^{*} w a$ ) à leur domicile, pour laquelle ils dépensent 100 dinars, somme considérable.

52. Ibn al-Ğawzī, al-Muntazam, op. cit., t. 16, p. 232, notice n 3531, et Ibn Katīir, al-Bidāya wa l-nihāya, op. cit., t. 12, p. 135. Un biographe du $\mathrm{VII}^{\mathrm{e}} / \mathrm{xIII}^{\mathrm{e}}$ siècle lui impute par ailleurs la fondation de waqf-s, sans préciser à quelle institution ils étaient destinés (Ibn al-Dubayțī, Dayl Ta'rih Bagdad, op. cit., t. 1, p. 80, notice $\mathrm{n}^{\circ} 2$ ) ; sans doute s'agissait-il des waqf-s permettant le fonctionnement de son masğid.

53. Ibn al-Ğawzī, al-Muntazam, op. cit., t. 16, p. 299.

54. Le šāfi ite devenu hanbalite Abū Manșūr al-Hayyāț, mort en 499/1105, qui y enseignait le coran aux aveugles (Ibn Abī Ya'lā, Țabaqāt al-ḥanābila, op. cit., t. 2, p. 217, notice n 696, et Ibn Rağab, Dayl, op. cit., t. 3, p. 79, notice n 46), puis son petit-fils Sibṭ Abū Manșūr al-Hayyāt, qui y enseigna de 487/1094 à 541/1146 (Ibn al-Ğawzì, al-Muntazam, op. cit., t. 18, p. 51, notice $n^{\circ} 4126$, et Ibn Rağab, Dayl, op. cit., t. 3, p. 175, notice $n^{\circ} 98$ ).

55. Voir les événements des années $495 / 1102$ et 521/1127 chez Ibn al-Ğawzī, al-Muntazam, op. cit., t. 17, p. 76 et 245. 


\section{Des stratégies matrimoniales complexes : le jeu des alliances}

On peut distinguer, entre les principaux membres du réseau hanbalite de Bāb al-marātib, trois types d'alliances matrimoniales ${ }^{56}$ : celles renforçant les liens internes au milieu lettré, celles contribuant à tisser des relations plus étroites entre commerçants et ulémas, et celles visant à établir des liens avec des milieux extra-hanbalites, dans la sphère politique surtout.

Les premières n'ont rien de spécifique au groupe hanbalite, et sont exemplaires du renforcement des liens de maître à disciples par le mariage d'une fille du maître avec l'un de ses élèves. Ibn al-Bannā' avait par exemple épousé la fille de l'un de ses maitres, un obscur hanbalite nommé Abū Manșūr al-Qarmīsīnī ${ }^{57}$, mais qui était lui-même le gendre de l'illustre Abū Ya'lā ibn al-Farrā', avec lequel Ibn al-Bannā' se trouvait ainsi indirectement lié.

Quant aux grands commerçants hanbalites Ibn Riḍān et Ibn Ğarada, ils épousèrent chacun une fille du prestigieux Abū Manșūr ibn Yūsuf ${ }^{58}$; à la mort de ce dernier, ses deux fils épousèrent à leur tour deux filles d'un autre Ibn Ğarada ${ }^{59}$ qui avaient hérité de leur père la coquette somme de 30000 dinars. On constate donc que les alliances matrimoniales se faisaient ici dans un milieu restreint : il s'agissait pour les commerçants de rechercher le prestige social issu d'une alliance avec la famille du « très honorable shaykh » Ibn Yūsuf et non de s'unir avec des familles plus modestes de lettrés, sinon démunis, en tout cas moins aisés.

Les alliances matrimoniales étaient aussi recherchées en dehors du cercle hanbalite, avec les milieux politiques particulièrement : ayant marié l'une de ses filles à Mu'ayyad al-mulk, fils de Nizāam al-mulk, vizir des Seldjoukides, Ibn Riḍwān se trouva par la suite également relié à une autre famille de vizirs, lorsqu'une sœur de son gendre Mu'ayyad al-mulk épousa le fils du vizir du calife Fahrr al-dawla ibn Ğahīr ${ }^{60}$. En connectant ces

56. Voir la figure $1:$ « Alliances matrimoniales entre notables hanbalites bagdadiens et milieux du pouvoir (deuxième moitié $\mathrm{du} \mathrm{v}^{\mathrm{e}} / \mathrm{xI}^{\mathrm{e}}$ siècle) ».

57. Mort en 460/1068. Trois biographes lui consacrent de brèves mentions : Ibn al-Nağğār (m. 643/1245), Dayl ta'rīh Bag̀dād, éd. Mușțafā 'Abd al-Qādir 'Ațā, Beyrouth, 1997, t. 18, p. 220, notice $n^{\circ} 790$; Ibn Ab̄̄ Ya'lā, Țabaqāt al-ḥanābila, op. cit., t. 2, p. 198, notice n 667 ; Ibn Rağab, Dayl, op. cit., t. 3, p. 6, notice $\mathrm{n}^{\circ} 2$.

58. Ibn al-Ğawzī, al-Muntazam, op. cit., t. 16, p. 107, notice $n^{\circ} 3394$ et p. 232, notice $n^{\circ} 3531$.

59. Dénommé 'Alī, ce personnage doit être distingué d'Abū 'Abdallāh Muhammad ibn Ğarada, évoqué jusqu'ici, mais il est plus que probable qu'un lien de famille ait existé entre eux.

60. Sur Ibn Ğahīr, m. 483/1090, voir en particulier Ibn Hallikān (m. 681/1282), Wafayāt al-a'yān, éd. Iḥsān 'Abbās, Beyrouth, s.d. [1968], t. 5, p. 127, notice nº 701; Ibn al-Ațīr, al-Kāmil, op. cit., t. 8, p. 464 ; Sibț ibn al-Ğawzī, Mir'āt, op. cit., t. 1, p. 138 ; Ibn al-'Imād, Šadarāt al-dahahab, op. cit., t. 5, p. 355 . 


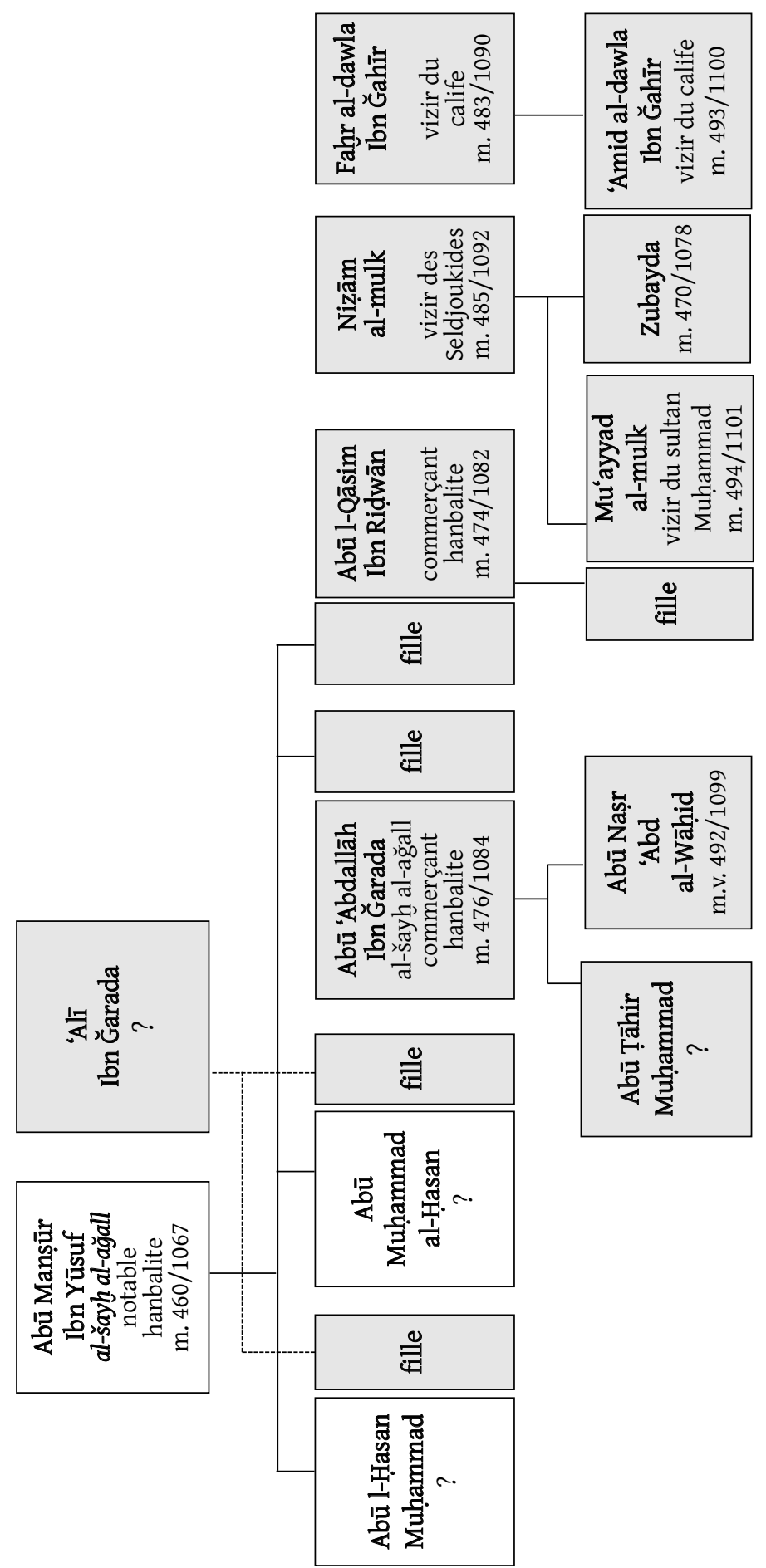


personnages à des réseaux totalement extérieurs à celui des hanbalites de Bāb al-marātib (ceux de la notabilité politique seldjoukide et abbasside), ces alliances leur ouvraient des perspectives accrues d'intercession en faveur de l'ensemble de leur groupe. Elles augmentaient ainsi ses chances de survie et ses possibilités d'atteindre ses objectifs sur la scène publique bagdadienne.

\section{Bilan : les caractéristiques du réseau}

L'organisation du réseau hanbalite peut être représentée sous la forme d'un schéma ${ }^{61}$, où chaque acteur apparaît sous la forme d'un cercle d'une taille proportionnelle au nombre de situations d'interaction avec d'autres hanbalites dans lesquelles le « Journal » le montre ${ }^{62}$. Les liens entre les acteurs (les traits reliant les cercles) sont, eux, d'une épaisseur proportionnelle au nombre d'interactions directes mentionnées entre deux personnages. Ce schéma ne prend en compte que les neufs acteurs présentés ci-dessus, et ne représente qu'un moment dans l'histoire du réseau hanbalite, celui de l'époque de rédaction des fragments conservés du «Journal », médiatisé par la vision de son auteur. Il permet cependant de faire quelques observations générales sur la morphologie du réseau ainsi reconstitué.

Le réseau hanbalite apparaît en premier lieu comme particulièrement dense : sur 36 liens possibles (nombre maximum de liens pouvant être établis entre 9 personnes), 21 sont attestés, soit près de $60 \%$; encore faut-il distinguer entre des personnages fortement intégrés au réseau (Ibn al-Bannā', mais aussi Abū Ğa'far ibn Ab̄̄ Mūsā, Abū l-Qāsim ibn Riḍwān, Ibn Ğarada et al-Baradānī, qui totalisent chacun entre 5 et 7 liens directs sur les 8 possibles) et des personnages en situation marginale : Abū Muhammad al-Tamīmī, Ibn Sukkara et Ibn 'Aqīl, dotés chacun de 2 ou 3 liens seulement ${ }^{63}$. D'autre part, en dehors d'Abū Muhammad al-Tamīmī, tous les membres du réseau avaient un accès aux autres membres par l'intermédiaire d'un relais au maximum ${ }^{64}$, ce qui démontre une forte intégration de l'ensemble.

61. Figure $2:$ «Principaux acteurs du réseau des lettrés et commerçants hanbalites de Bāb al-marātib (Bagdad) d'après le « Journal » d'Ibn al-Bannā' (460-61/1068-69) ».

62. Il faut noter que le cercle dévolu à Ibn al-Bannā' devrait être, en respectant les proportions allouées aux autres personnages, deux fois plus imposant qu'il ne l'est sur le schéma. Bien entendu, cette surreprésentation par rapport aux autres acteurs du réseau provient de la nature auto-centrée de l'œuvre et doit être corrigée en conséquence, d'où le choix de faire figurer Ibn al-Bannā' en position non pas centrale, mais latérale.

63. La situation d'Abū Manșūr ibn Yūsuf, décédé peu avant la période évoquée par le « Journal », est trop singulière pour pouvoir entrer dans la présente analyse.

64. C'est-à-dire qu'en dehors d'Abū Muhammad al-Tamīmī, chacun pouvait avoir un accès à tous en un maximum de deux liens. 


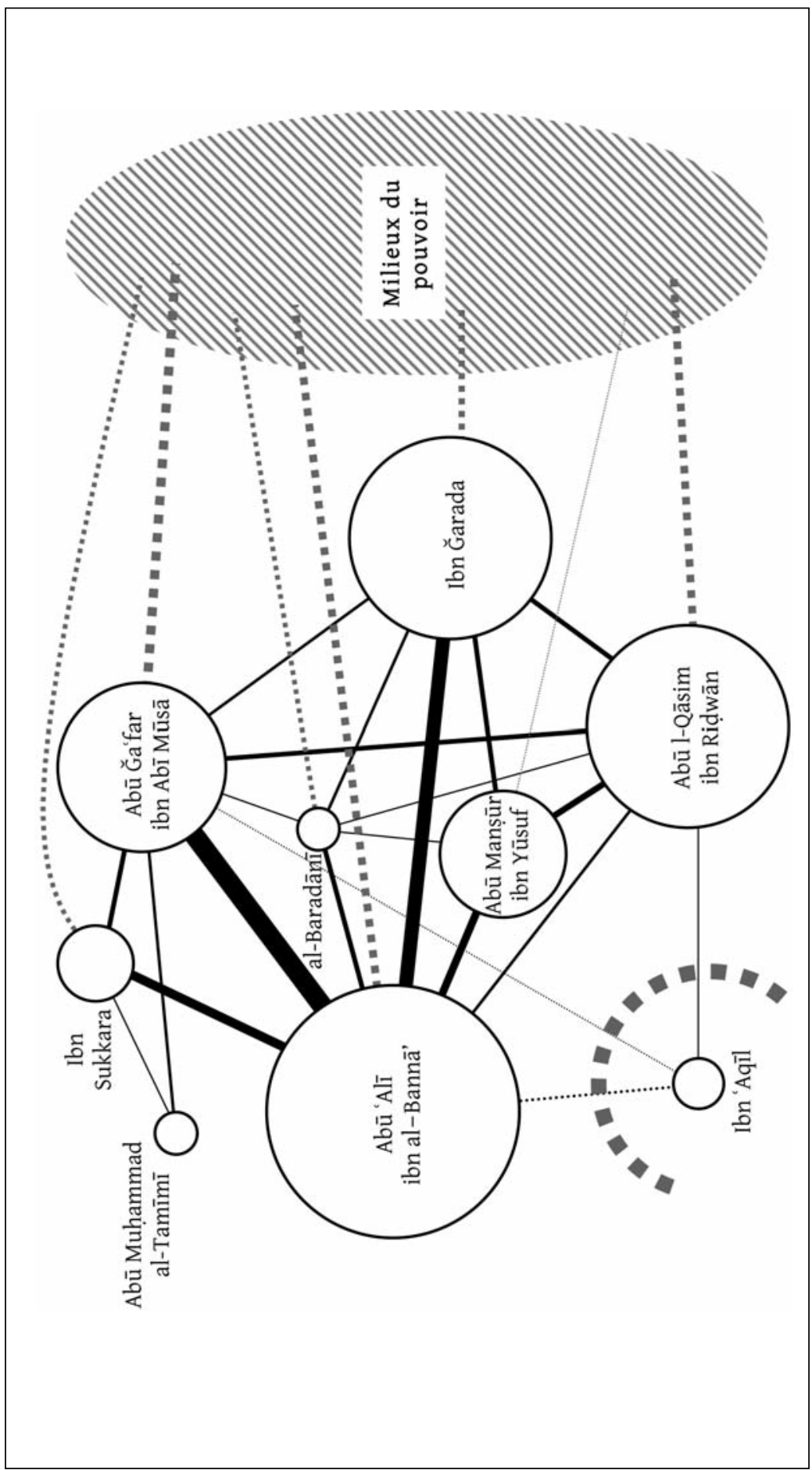

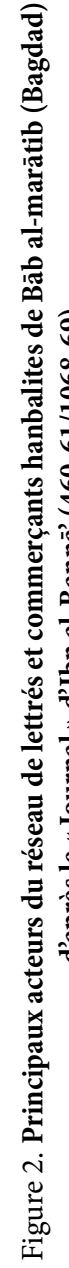


Une deuxième caractéristique du réseau est sa relative décentralisation, ou plutôt l'équilibre des centres : si l'on prend en compte les effets de sources qui conduisent à exagérer le rôle d'Ibn al-Bannā', il apparaît que plusieurs acteurs étaient en relation suivie avec la plupart des autres. Le personnage d'Abū Ğa 'far ibn Abī Mūsā se détache cependant comme «tête de pont », jouant un rôle de relais envers les acteurs les plus marginaux du réseau (en dehors d'Ibn 'Aqīl), à savoir Ibn Sukkara et Abū Muhammad al-Tamīmī. L'isolement de personnages comme Ibn 'Aqīl (présenté en rares situations d'interaction avec les acteurs principaux du réseau hanbalite, la nature des relations entretenues étant dans l'ensemble mauvaise) témoigne des fractures qui traversaient le groupe hanbalite, et qui pouvaient se traduire par la mise au ban d'un individu, en brisant les liens le rattachant au réseau.

Enfin, le réseau apparaît comme globalement replié sur lui-même, avec peu de contacts suivis avec les milieux non hanbalites. Dans le « Journal », sur environ 250 situations d'interaction sociale impliquant les acteurs du réseau hanbalite, moins de $10 \%$ les présentent en contact avec des non-hanbalites (milieux du pouvoir exceptés); de plus ces situations se déclinaient, dans près de la moitié des cas, sous la modalité du conflit.

Densité, décentralisation, forte intégration et repli sur soi font du réseau hanbalite un puissant cadre de vie communautaire, mais aussi un outil d'une efficacité potentielle réduite. Les liens de certains puissants hanbalites avec les milieux politiques seldjoukides et abbassides étaient cependant à même de compenser cet aspect, offrant à l'ensemble des membres du groupe des potentialités auxquelles chacun n'aurait pu, individuellement, prétendre.

\section{Fonctions et limites du réseau hanbalite}

Les usages du réseau, tels que l'on peut les observer à la lecture du " Journal », étaient de plusieurs types : souvent communautaires, mais aussi tournés vers l'extérieur en cas de recherche de l'intercession politique des membres les plus influents.

\section{Les usages communautaires du réseau}

Le premier type d'usage du réseau hanbalite peut être qualifié de communautaire $^{65}$, dans le sens où il visait à renforcer les liens internes du groupe et à y permettre la circulation de l'information à son propos. Les

65. Le fort sentiment identitaire des membres du groupe hanbalite, assorti d'un mécanisme interne de règlement des conflits, autorise à considérer ce groupe comme une communauté au sens anthropologique du terme. 
contacts se faisaient parfois directement, selon la modalité de la rencontre, mais aussi assez souvent de façon indirecte, par l'envoi d'émissaires porteurs de messages écrits ou oraux ${ }^{66}$; ils permettaient aux principaux membres du groupe de réagir rapidement aux événements les concernant.

C'est dans ce cadre que se situent les principaux élargissements de l'horizon géographique du « Journal» : lors de l'échange, par le truchement du témoignage de voyageurs ou par ouï-dire, de nouvelles concernant des hanbalites résidant hors de Bagdad. Ibn al-Bannā' rapporte à plusieurs reprises de tels échanges d'informations, qui se faisaient la plupart du temps verbalement, par discussion entre l'auteur et un voyageur fraîchement arrivé à Bagdad. Les nouvelles transmises concernaient toutes des hanbalites ou leurs associés en affaires, installés dans des villes des régions iraquiennes et iraniennes ${ }^{67}$, et étaient essentiellement de nature sociale (naissances, mariages, décès, déplacements).

\section{La circulation de l'information " généraliste"}

Un autre effet du réseau était de permettre la circulation de nouvelles non restreintes au milieu hanbalite, de nature politico-militaire et commerciale (tremblement de terre avec ses conséquences en matière économique et de possibilité de déplacement ; mouvements des troupes seldjoukides, prises de citadelles, arrivée prochaine du sultan à Bagdad... $\left.{ }^{68}\right)$. Ces nouvelles provenaient en général de régions moins orientales (Syrie-Palestine, Ğazīra, villes saintes de l'Arabie) et constituaient pour Ibn al-Bannā' un matériau qu'il consignait scrupuleusement, dans l'optique sans doute de les intégrer dans un éventuel ouvrage historiographique postérieur. Il faut noter qu'en matière de circulation de l'information, l'appartenance au réseau hanbalite de grands marchands comme Ibn Riḍwān et Ibn Ğarada était déterminante, car l'essentiel de cette information « généraliste » leur parvenait par le truchement de lettres de commerçants apportées par les caravanes de voyageurs qui passaient régulièrement par Bagdad ${ }^{69}$; le fait qu'Ibn al-Bannā’ fût à même de prendre connaissance de ces nouvelles participe donc bel et bien d'un effet de réseau.

66. Voir par exemple le $\S 76$ : échange de messages entre le šarīf Abū Ğa'far et Ibn al-Bannā', concernant la possibilité qu'Ibn 'Aqīl ait trouvé refuge chez Ibn Riḍān. Ibn al-Bannā' décida finalement de se déplacer en personne chez Ibn Ğarada pour le mettre au courant des derniers rebondissements de l'affaire.

67. Les villes citées sont Bandanīğīn et Bașra pour l'Iraq, Hamad̄ān et Nishapur pour l'Iran ( $\$ 59,104,2$ et 51 respectivement).

68. Voir par exemple les $\S 3,6,11,19,21,28$ et 41 .

69. Sur ces questions, voir V. Van Renterghem, « L'accès à l'information et les méthodes de travail d'un lettré bagdadien du ve $\mathrm{xI}^{\mathrm{e}}$ siècle », Studia Islamica 104-5, 2007, p. 133-150. 


\section{L'intercession politique}

Cependant, l'effet de réseau le plus important pour les acteurs euxmêmes concernait les relations du groupe hanbalite avec les milieux politiques, qu'ils soient abbassides ou seldjoukides. En ces débuts de seconde moitié $\mathrm{du} \mathrm{v} / \mathrm{xI}$ siècle, dans le contexte particulier évoqué plus haut de recomposition des forces sunnites, les hanbalites formaient un groupe turbulent, désireux de faire appliquer leurs propres valeurs morales et de ne pas laisser de place, sur la scène bagdadienne, aux courants rivaux de l'islam - shi'ites mais aussi sunnites. À Bagdad, les chroniques signalent de nombreux affrontements entre populations sunnites (c'est-à-dire bien souvent, en contexte bagdadien, pro-hanbalites) et shi'ites ${ }^{70}$, mais aussi entre hanbalites et mu'tazilites puis aš arites ${ }^{71}$. À ces conflits de nature religieuse, il faut ajouter les troubles dus à la présence à Bagdad de troupes étrangères au service des Seldjoukides, dont les soldats n'étaient pas arabophones; plusieurs émeutes furent provoquées par les exactions de ces soldats contre la population locale ${ }^{72}$, ou encore en raison de l'impossibilité de communiquer avec les Bagdadiens. Les émeutes (fitna-s) étaient ainsi monnaie courante à l'époque de rédaction du « Journal $»^{73}$, et les hanbalites y prenaient presque toujours part, sans compter les désordres créés par les fractures internes au groupe ${ }^{74}$.

Or leur participation à ces événements, entraînant des troubles à l'ordre public, déclenchait dans bien des cas des démêlés de membres du groupe avec le pouvoir politique et les forces de maintien de l'ordre, seldjoukides ou abbassides : il n'était pas rare de voir, même si le « Journal » ne l'évoque qu'à demi-mot, des compagnons hanbalites emprisonnés, assignés à résidence, molestés par les forces de l'ordre ou soumis à des amendes en

70. Voir par exemple les événements des années 451/1059 (émeute anti-shi'ites à Bagdad après la mise en déroute d'al-Basāsīrī par les Seldjoukides) et 458/1065 (émeute suite à la célébration publique de 'āšūrā' par les shi'ites bagdadiens) chez Ibn al-Ğawzī, al-Muntazam, op. cit., t. 16, p. $48-49$ et 94 .

71. Dans le « Journal » : 57 (un groupe de hanbalites mené par Ibn Sukkara s'oppose à la prédication publique de l'aš‘arite Ilkyā al-Harrāsī), \$165 (intervention des hanbalites contre un prédicateur ( $w \bar{a} i z)$ ne répondant pas à leurs exigences), etc.

72. Dans le « Journal » : § 83 (émeute provoquée par l'agression d'une femme bagdadienne par un étranger ('ağam) armé ; intervention d'un groupe de hanbalites conduit par Ibn al-Bannā' dans la querelle), $§ 180$ (émeute en réaction aux exactions des soldats contre la population locale).

73. Ibn al-Bannā' en relate huit au cours des 13 mois sur lesquels s'étend le « Journal », mais elles étaient aussi fréquentes avant et après cette période.

74. Le « Journal » évoque au moins deux émeutes dues aux efforts des hanbalites pour exclure Ibn 'Aqīl et l'empêcher de s'exprimer publiquement : § 16 et 80. 
réparation des dommages commis ${ }^{75}$. Les difficultés que connut le personnage le plus charismatique du groupe, le šarîf Abū Ğa far, avec les sphères politiques - difficultés qui n'avaient visiblement d'égal que l'embarras du pouvoir envers une situation potentiellement explosive sont emblématiques de la tension existant entre les milieux hanbalites, notables et peuple confondus, et les milieux tant califaux que sultaniens. Il n'en était que plus nécessaire, pour le groupe hanbalite, que certains de ses membres aient accès aux sphères du pouvoir et puissent jouer un rôle d'intercession en faveur des compagnons plus modestes.

Si plusieurs des principaux acteurs du réseau hanbalite sont signalés, dans le "Journal », pour entrer ponctuellement en relation avec les milieux politiques ${ }^{76}$, la plupart du temps ces relations étaient mauvaises ou ambivalentes et le rapport de force ne penchait pas en leur faveur ; c'était notamment le cas pour Ibn al-Bannā', Ibn Sukkara ou même le šarîf Abū Ğa'far ibn Abī Mūsā, qui jouissait d'un prestige certain (entre autres en raison de son ascendance hashimite) mais était aussi perçu comme un fauteur de troubles. Seuls deux personnages semblent avoir bénéficié d'un réel ascendant dans les milieux politiques : il s'agit des deux commerçants, Ibn Riḍān et Ibn Ğarada, dont la fortune autant que les appuis familiaux confortaient la position face aux puissants.

Ibn Riḍān surtout apparaît fréquemment dans un rôle d'intercesseur en faveur de ses compagnons hanbalites, ou même de l'ensemble des habitants de son quartier. Lui-même exerçait des fonctions politico-judiciaires : il avait été reçu comme témoin instrumentaire (šāhid) par le qāḍ̂l l-qud̄àt, avec pour garant ${ }^{77}$ le vizir Ibn Ğahīr avec qui, rappelons-le, il s'allia indirectement par la suite, grâce au mariage de sa fille avec Mu'ayyad al-mulk, frère d'un gendre d'Ibn Ğahīr. Il occupait aussi le poste d'intendant (nāzir) de l'hôpital de Bagdad, le Bīmāristān al-'Adudū̄̄78, et officiait comme chargé d'affaires (wakīl, nā'ib) du calife abbasside al-Qā'im ${ }^{79}$. On le retrouve encore comme intermédiaire ou «agent» (safir) d'autres hautes figures du monde politico-administratif, comme le ra’̄s Abū Šuğăa', qui devint par la suite vizir

75. De telles rigueurs contre les compagnons hanbalites sont évoquées dans certains passages traitant des relations tendues du groupe hanbalite avec le pouvoir et des conséquences des fitna-s; voir notamment les § 103 et 109.

76. Voir la figure 2.

77. Pour qu'un personnage soit officiellement reconnu comme susceptible d'exercer devant le qā d̄i l'activité de témoin instrumentaire, il fallait qu'il reçoive l'appui (tazkiya) de deux notables se portant garants de sa moralité. Le qāḍi l-quḍāt lui accordait alors le titre de šāhid (pl. šuhūd), « témoin instrumentaire ».

78. Ibn al-Ğawzī, al-Muntazam, op. cit., t. 16, p. 105.

79. « Journal », § 116. 
du calife al-Muqtadī et était à la tête de l'une des plus importantes fortunes de Bagdad $^{80}$.

Cet investissement dans les sphères politico-administratives, mais aussi commerciales et financières, garantissait l'efficacité des interventions d'Ibn Riḍān en faveur de ses compagnons. Le " Journal » en offre deux exemples. En šawwāl 460/août 1068, Ibn al-Bannā' rapporte qu'Ibn Rị̣̂ān relaya auprès des milieux du pouvoir les plaintes d'habitants de son quartier contre le portier (bawwāb) de Bāb al-marātib, ce qui entraîna la destitution du personnage ${ }^{81}$. Quelques mois plus tard, il obtint gain de cause contre un fonctionnaire califal doté de fonctions de contrôle urbain, le hāăgib de Bāb al-marātib, qui avait interdit à un petit commerçant du quartier de dresser un grill à aubergines dans la rue. Le commerçant se plaignit à Ibn Rị̂wān qui, par une simple lettre au calife, parvint à régler l'affaire en sa faveur ${ }^{82}$. En faisant jouer ses contacts dans le milieu politique et sa position favorable auprès du calife (dont on peut penser qu'elle était en grande partie due à sa fortune, dans le contexte des graves difficultés financières éprouvées par le calife abbasside), Abū l-Qāsim ibn Riḍwān occupait ainsi une position cruciale dans le réseau hanbalite, jouant le rôle de relais avec les sphères du pouvoir, largement inaccessibles à la majorité de ses contemporains. Ce rôle d'intercesseur reposait avant tout sur sa forte insertion dans le milieu de la notabilité bagdadienne, fondée sur sa fortune et ses activités politico-judiciaires et non sur son appartenance au groupe hanbalite.

\section{Conclusion}

La force du réseau hanbalite résidait ainsi dans la position particulière occupée par certains de ses acteurs parmi les notables bagdadiens, bien plus que dans sa densité ou sa structure. Celles-ci permettaient cependant une circulation rapide de l'information, et autorisaient donc de promptes réactions de la part des membres du groupe lorsque la situation, à leurs yeux, l'exigeait - ce qui était fréquemment le cas pour ces infatigables activistes de la cause hanbalite en matière de morale et de prédication publique. Il faut donc insister, en guise de conclusion, sur le rôle crucial, dans ce réseau, de ces personnalités incontournables, par ailleurs

80. § 116 également : Ibn Riḍwān agit comme intermédiaire pour le compte d'Abū Šuğā‘ dans l'achat de l'ancien palais d'al-Basāsīrī, pour la somme faramineuse de 300000 dinars. Sur Abū Šuğà', mort en 488/1095, voir en particulier Ibn al-Ğawzī, al-Muntazam, op. cit., t. 17, p. 22, notice n' 3652, et Sibț ibn al-Ğawzī, Mir'āt, op. cit., t. 1, p. 257.

81. $\S 8$.

82. § 147 . 
quasiment invisibles dans les autres sources de l'époque, qu'étaient les grands commerçants, mécènes et intercesseurs du groupe : Ibn Riḍwān et Ibn Ğarada - rôle que seule la source étudiée, en raison de son caractère subjectif et centré sur les activités quotidiennes de son auteur, permet d'esquisser.

Il est impossible de généraliser les observations faites ici aux autres groupes d'affiliation en matière de figh à Bagdad, et ce pour plusieurs raisons : l'absence, pour les milieux šăfi ites et hanafites, de source comparable en nature au « Journal » d'Ibn al-Bannā', mais aussi et surtout la différence d'aspect que semblent présenter ces milieux en regard de la communauté des hanbalites de Bāb al-marātib. Celle-ci, comptant un nombre restreint de membres et un caractère local très accusé, se distinguait par une forte densité de relations sociales endogènes, alors que les šăfi 'ites et les hanafites présents à Bagdad comptaient en leurs rangs un grand nombre d'étrangers à la ville, qui y demeuraient pour un séjour limité ou bien s'y fixaient définitivement ${ }^{83}$. Enfin, les positions respectives des madhab-s šāfi ite et hanafite envers les milieux du pouvoir étaient très différentes de celle occupée, en ces premières années de domination seldjoukide sur le califat abbasside et sur Bagdad, par l'école hanbalite. On ne saurait donc, à partir du seul exemple du réseau hanbalite bagdadien à ce moment précis de son existence, tirer des conclusions générales sur les implications sociales de l'affiliation à un madhab.

83. Un comptage statistique opéré à partir des individus présentés comme hanbalites, hanafites ou šāfi ites ayant vécu à Bagdad ou visité la ville et morts dans la seconde moitié $\mathrm{du} \mathrm{ve} / \mathrm{xl}^{\mathrm{e}}$ siècle, recensés dans les sources biographiques d'époque, donne un nombre de 74 hanbalites, dont 62 (soit $84 \%$ ) passèrent toute leur existence à Bagdad, tandis que parmi les 114 šăfi ites on rencontre seulement 41 Bagdadiens de naissance et de résidence (soit $36 \%$ ) contre 20 immigrants (soit $18 \%$ ) et 41 simples visiteurs (36\%). Les chiffres sont assez semblables chez les hanafites : 55 individus recensés, dont 18 Bagdadiens (33 \%), $11 \mathrm{im}$ migrants (20\%) et 19 visiteurs ( $35 \%$ ). La différence entre hanbalites et membres des autres madhab-s, en terme de provenance locale, est donc patente. Pour une étude détaillée de l'évolution des trois madhab-s sunnites à Bagdad aux $\mathrm{V}^{\mathrm{e}}-\mathrm{VI}^{\mathrm{e}} / \mathrm{XI}^{\mathrm{e}}-\mathrm{XII}{ }^{\mathrm{e}}$ siècles, voir V. Van Renterghem, Les élites bagdadiennes au temps des Seldjoukides, Paris, Les Indes savantes, 2010 (à paraître). 